\title{
"Touching" services: tangible objects create an emotional connection to services even before their first use
}

\author{
Nora Nägele ${ }^{1} \cdot$ Benjamin von Walter $^{2}$. \\ Philipp Scharfenberger ${ }^{3} \cdot$ Daniel Wentzel $^{4}$
}

Received: 7 November 2018/Accepted: 16 April 2020/Published online: 2 May 2020

(C) The Author(s) 2020

\begin{abstract}
Although research suggests that physical elements of the servicescape play an important role in the service process, there is little research on the impact of tangible objects that companies give to consumers such as membership cards, pens, mugs, or fashion articles. Drawing on research about embodied cognition, this paper investigates how and under which conditions the provision of tangible service objects affects consumers. Three experimental studies were conducted, in which participants received different objects they could either touch or just see. These studies indicate that touching a service object metaphorically translates into a perceived mental connection towards the service. More specifically, physically connecting to a service object leads to a stronger psychological connection to the corresponding service, which, in turn, increases behavioral intentions. The results also demonstrate that providing a tangible object only has an impact when the object is of high aesthetic appeal. These findings suggest that providing tangible service objects is an effective way for service providers to build an emotional connection
\end{abstract}

\footnotetext{
$\triangle$ Daniel Wentzel

wentzel@time.rwth-aachen.de

Nora Nägele

nora.naegele@hydac.com

Benjamin von Walter

benjamin.vonwalter@ost.ch

Philipp Scharfenberger

philipp.scharfenberger@unisg.ch

1 Hydac Fluidtechnik GmbH, Industriegebiet, 66280 Sulzbach, Germany

2 Institute of Business Management, FHS St.Gallen University of Applied Sciences, Rosenbergstrasse 59, 9001 St. Gallen, Switzerland

3 Institute for Customer Insight, University of St. Gallen, Bahnhofstrasse 8, 9000 St. Gallen, Switzerland

4 Chair of Marketing, RWTH Aachen University, Kackertstraße 7, 52072 Aachen, Germany
} 
with potential customers and to strengthen the emotional connections of existing customers.

Keywords Service objects · Embodied cognition - Servicescape · Corporate gifts $\cdot$ Touch $\cdot$ Service experience

\section{Introduction}

Imagine that you are looking for a mortgage and have made an appointment with a local bank. Before the appointment, you receive a parcel from the bank which contains a beautiful riffled, carbon-colored folder and a note saying "For your mortgage documents. We look forward to discussing your mortgage needs with you." How would the experience of holding this folder affect your likelihood of becoming a customer of this bank and, more importantly, why?

When marketing services, marketers commonly face the challenge that services are often perceived as more abstract and intangible than products (Zeithaml and Bitner 1996; Mittal 1999). As a result, consumers may find it difficult to mentally grasp and emotionally relate to services (Laroche et al. 2001; Mitra et al. 1999). A preliminary study ${ }^{1}$ that we conducted during this project confirms this strongly. When asked to either think of a product or a service regularly used, participants perceived the specified services as significantly less graspable compared to products and indicated a significantly weaker connection to their service providers than to their product providers. To address such challenges, research has argued that the servicescape (i.e., the physical facilities where the service takes place) can help consumers to grasp and evaluate a service (Wakefield and Blodgett 1999; Bitner 1992). Specifically, research has found that servicescape elements such as a building's design and décor do not only have an influence on the perception of the servicescape itself but also shape perceptions of service quality dimensions and overall service quality (e.g., Baker et al. 2002; Wakefield and Blodgett 1994).

While these studies have increased our understanding of servicescape elements as informative cues to infer intangible service aspects, little research has investigated the role of another type of material service elements, namely tangible objects that service firms give to consumers during the acquisition or the service delivery phase. Typically, such objects are rather simple, of low monetary value, easily graspable,

\footnotetext{
${ }^{1}$ One hundred and fifty-four individuals from a German and Swiss consumer panel participated in the study (average age: 40 years; $47 \%$ female). The most frequently mentioned products were electronics, cars, watches, jewelry, and apparel, while the mentioned services mainly related to transportation, telecommunication, media, finance, logistics, retail, hair and cosmetics, as well as sports, and internet services. Perceived graspability was measured with one 7-point item ("How graspable do you perceive the service [product] to be?") with endpoints labeled "not graspable at all" [1] and "very graspable" [7]. Psychological connection was measured with the same scale as reported in the method section of this paper. Frequency of usage of the product/service was included as a control variable. An ANCOVA revealed that participants in the service condition perceived services as significantly less graspable $(M=5.21)$ than participants in the product condition perceived products $(M=6.73 ; F(1,137)=36.58$, $p<0.01)$. Furthermore, consumers indicated that they perceived a weaker psychological connection to the specified service providers $(M=2.47)$ compared to the specified product providers $(M=3.02$; $F(1,137)=4.57, p=0.03)$.
} 
and portable. Hence, while the experience of the core servicescape is usually restricted to the location and time of the service provision, these objects further extend into the personal environment of consumers. Examples of such objects include the folder mentioned in the introductory example as well as many other objects such as membership cards, mugs, pens, jerseys, and caps. While such objects are often considered as trivial giveaways that bear little importance for consumers, we argue that they emotionally connect consumers to the corresponding serviceespecially in situations, in which the service itself is not present (e.g., before the consumer has had the chance to experience the actual service and servicescape; Rosenbaum and Massiah 2011). Importantly, unlike other servicescape components, consumers usually hold, wear, and use such objects in their everyday lives. We argue that the sensory experience of touching these tangible service objects makes the service more graspable for consumers and allows them to connect psychologically to the service.

To investigate this idea, we draw on research about embodied cognition, a theory that argues that sensorimotor experiences form a mental scaffold for conceptual knowledge (Ackerman et al. 2010). Building on this line of research, we postulate that touching (that is, physically connecting to) an object that is associated with a service fosters feelings of being psychologically connected to the service and, consequently, induces positive behavioral intentions towards the service. Three experiments that focus on different service contexts and different tangible service objects provide converging evidence for these predictions.

In doing so, our research informs theory about the impact of providing tangible service objects and the underlying psychological process. Specifically, our research demonstrates that touching tangible service objects has a positive effect on consumers' connections with and behavioral intentions towards a service. Importantly, this effect is revealed for customers that have not yet experienced the service in question as well as for those that have experienced the service. This finding is noteworthy because it suggests that tangible service objects are more than informational cues that consumers may use to infer service quality (e.g., Baker et al. 2002; Wakefield and Blodgett 1994) or gifts that may stimulate reciprocation behaviors (e.g., Bodur and Grohmann 2005; Marchand et al. 2017). In fact, our research indicates that touching tangible objects may help consumers to bodily connect to a service, which, in turn, may foster the development of a psychological connection between consumers and the service. Hence, our findings address recent calls for new, consumer-based perspectives on the psychological responses to specific elements of the servicescape (Wakefield and Blodgett 2016). Furthermore, we also provide evidence that the aesthetic appeal of an object (that is, how strongly an individual is attracted by the physical properties of the object) is another important prerequisite to make the provision of service objects effective. These findings may help firms to select appropriate objects and address calls for more research on principles for effectively designing service experiences (Zomerdijk and Voss 2010). 


\section{Conceptual development}

\subsection{Tangible service objects as part of the extended servicescape}

A long tradition of research has investigated the role of physical components in the service process (e.g., Bitner 1992; Wakefield and Blodgett 1996, 1999; Rosenbaum 2009; Hooper et al. 2013). In her seminal article, Bitner (1992) coined the term "servicescape" to refer to all aspects of a service company's physical facilities. According to Bitner's (1992) model, a servicescape may encompass physical dimensions such as ambient conditions (e.g., temperature, lighting, music, scent), spatial layout and functionality (e.g., equipment, furniture), as well as signs, symbols, and artifacts (e.g., directional signage, artworks). Rosenbaum and Massiah (2011) presented an extended servicescape model suggesting that a servicescape may additionally encompass a natural dimension (e.g., plants that have restorative qualities), a social dimension (e.g., employees, other customers), and a sociallysymbolic dimension (e.g., signs, symbols, and artefacts with specific meanings such as a rainbow pride flag). In this paper, we investigate tangible objects that service firms give to consumers such as badges, wristbands, cards, pens, mugs, or clothing. While such objects may not be regarded as part of the core servicescape in which service delivery takes place, they may be seen as mobile artefacts that symbolically connect to the service. That is, they may serve as portable symbols of the service that physically extend to the environment and the self of consumers-even in situations in which the core servicescape is not accessible. Hence, tangible service objects may be regarded as part of the socially-symbolic dimension of the extended servicescape (Rosenbaum and Massiah 2011) and, as such, they extend the notion of the service into the life and surroundings of consumers.

\subsection{The impact of tangible service objects}

Although tangible service objects may be regarded as a part of the extended servicescape, research that investigates how such objects affect behavioral intentions towards a service is scarce (for an overview, see Table 1). The bulk of studies investigating servicescape effects has focused on the impact of the servicescape in which the actual service takes place (Mari and Poggesi 2013), that is, on the impact of permanent facilities that are present during service delivery. In this regard, research has argued that material elements of the servicescape may serve as important informative cues which affect customers' perceptions of service quality and other intangible service characteristics (e.g., Baker et al. 2002; Hooper et al. 2013; Wakefield and Blodgett 1994). Moreover, researchers have demonstrated that servicescape elements can influence behavioral intentions through emotional responses such as pleasure or arousal (e.g., Jang and Namkung 2009; Orth and Wirtz 2014).

In addition, some studies have investigated the role of providing objects from a gift giving perspective. Research in this field has argued that giveaways increase customer loyalty because customers may want to reciprocate for a gift they have 


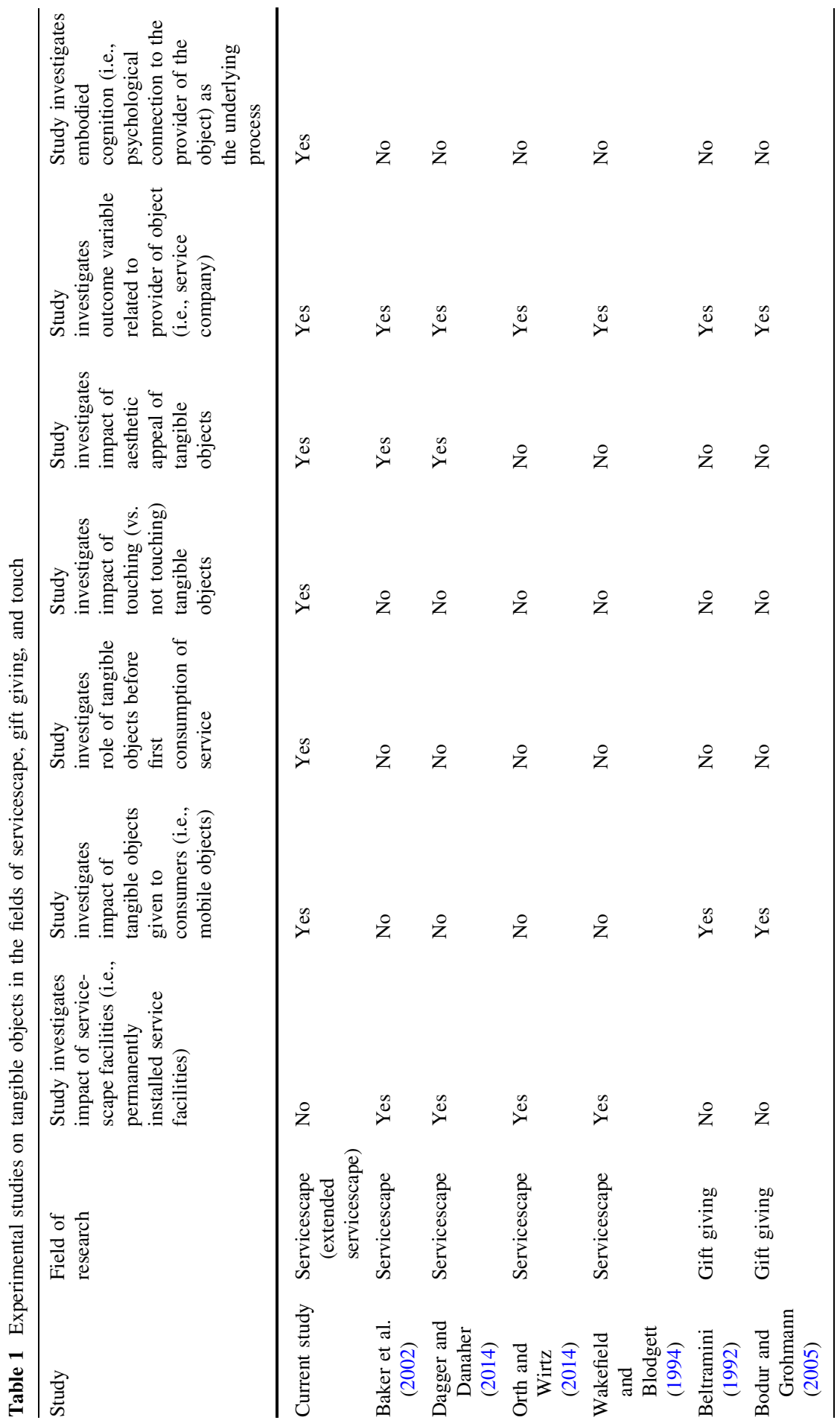




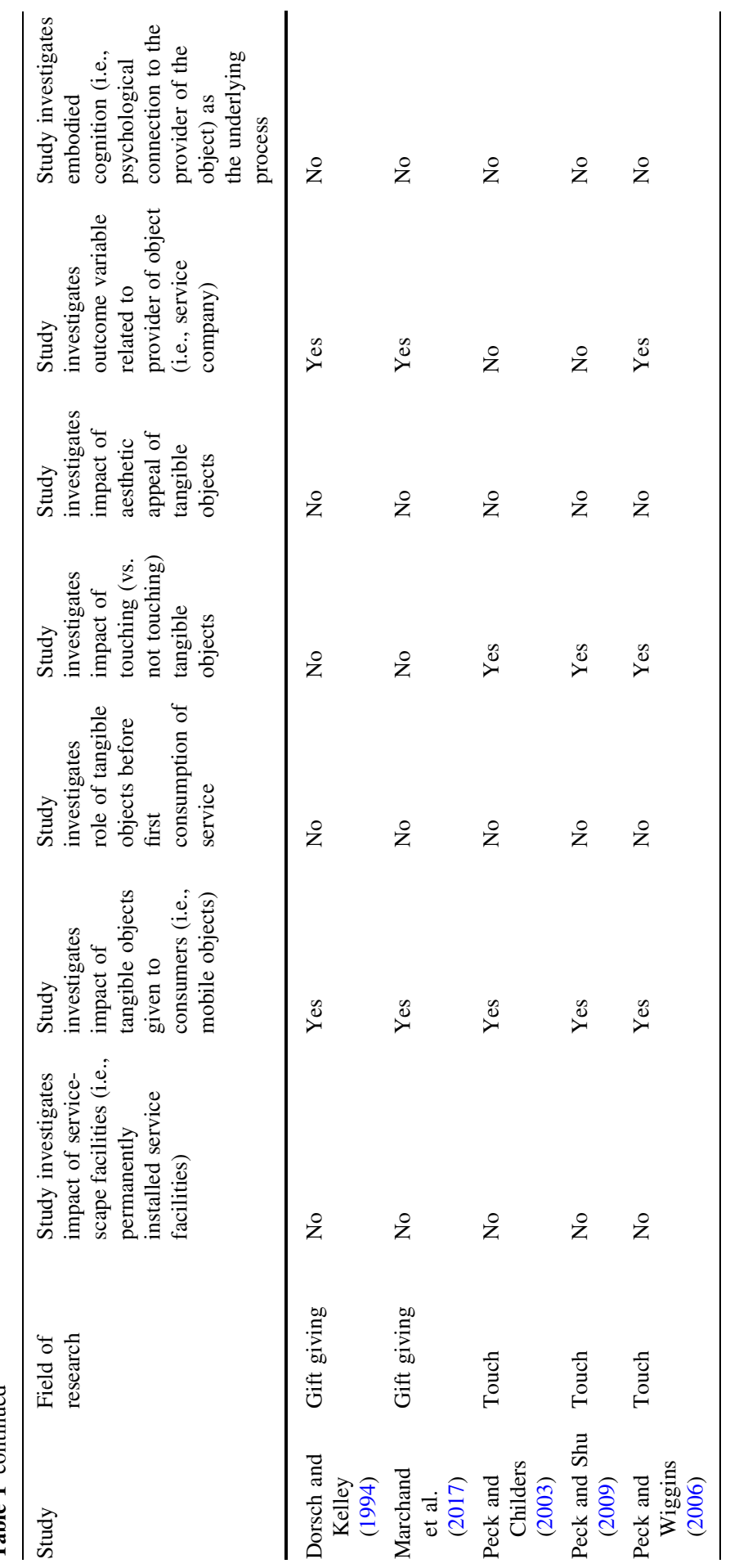


received (Beltramini 1992; Bodur and Grohmann 2005; Dorsch and Kelley 1994; Marchand et al. 2017). Experimental studies have mainly focused on the impact of intangible gift characteristics such as gift value or gift type (e.g., personal vs. corporate gift) and on existing customers, that is, on individuals who have already experienced the service (e.g., Bodur and Grohmann 2005; Dorsch and Kelley 1994). In a recent study, Marchand et al. (2017), for example, demonstrated that economic gifts (e.g., coupons) had a stronger effect on perceived relationship investments, and, ultimately, on additional customer spending when they were related to a company's offering, whereas social gifts (e.g., chocolate) had a stronger effect when they were unrelated to the service.

However, providing consumers with tangible service objects may elicit responses that go beyond the effects previously studied in the literature. For example, a drinking bottle provided by a gym may not only serve as an informational cue about the corresponding gym (e.g., the quality of the gym) or as a tool to foster reciprocity-based behaviors. Touching and using such a bottle may, above that, induce and strengthen a psychological connection between the consumer and the gym even before the consumer has experienced the gym. Hence, while previous research has either focused on understanding how servicescapes contribute to the image of a service provider or how gifts stimulate reciprocity behaviors on the part of customers, this research focuses on how customers' bodily interaction with tangible objects belonging to the servicescape contribute to their psychological connection to the service. While the literature on servicescapes and gift giving provides a helpful basis for defining this particular research question, it offers little information to more specifically conceptualize this potential effect of service objects. A theoretical stream that explicitly considers such interrelations between physical and mental sensations is the theory of embodied cognition.

\subsection{The effect of touching tangible service objects}

According to embodied cognition, mental processes are informed by the way humans physically interact with their environment (Barsalou 2008; Krishna 2012; Hong and Sun 2012). That is, the way we think and feel about things is determined by our experiences in the physical world. Ackerman et al. (2010) argue that individuals form a framework of conceptual knowledge through sensory experiences, particularly in early development stages. They reason that knowledge gained through the early-on interaction with the physical world is abstracted and transferred into various knowledge domains. For example, the experience of infants of lying warm and cozy in the arms of their parents may not only result in the sensory experience of warmth and coziness but may also help to develop more abstract ideas of warmth and coziness that are transferred to and used in other conceptual domains (e.g., a warm-hearted person, a cozy evening).

According to Lakoff and Johnson (2003), one phenomenon of this interrelation between physical experiences and thoughts is the metaphoric transfer of physical notions to mental contexts. For example, one can "grasp" an idea, "drown" in work, or feel emotionally "close" or "connected" to something. In the end, many 
expressions used to describe sensory phenomena are also used metaphorically to describe mental sentiments.

Research that builds upon this idea of a metaphorical connection between physical experience and emotional sentiment has highlighted that sensual cues may inform emotional responses to more abstract entities. For example, Williams and Bargh (2008a) show that holding a warm mug in a social situation can increase the perceived emotional warmth of a social counterpart. They, furthermore, show that spatial distance manipulations between family members can bias the perceived emotional bonds between these members (Williams and Bargh 2008b). Moreover, physiological motions such as vertical (nodding) and horizontal (shaking) head movements have been shown to influence the likelihood to agree or disagree with messages (Wells and Petty 1980). Hence, according to embodied cognition, sensory experiences are fundamental to humans' cognitive processes and influence the way individuals think, feel, and behave through metaphors that are learned by experiencing the physical world (Ackerman et al. 2010; Krishna and Schwarz 2014; Lakoff and Johnson 2003).

Building on this argument, we hypothesize that the difficulty of consumers to bodily refer to services as a graspable entity may impede their cognitive reference to them, especially when they are not using the service yet. While traditional products can be easily touched and sensually experienced, services often lack this direct sensual accessibility (e.g., Zeithaml and Bitner 1996; Mittal 1999; see also the findings of our preliminary study reported in Sect. 1). Hence, if physical experience is fundamental to cognitive processes, then the abstractness of services may hamper the psychological reference to them (Laroche et al. 2001). More precisely, we argue that the difficulty to perceive a service as a physical entity that one can bodily connect to may impede consumers' ability to connect psychologically to the service. We thereby define psychological connection-in line with the core notion of embodied cognition - as a metaphor of physical connection. That is, we conceptualize psychological connection as an individual's feeling of connecting to an entity in a mental domain analogously to the sensation of physically connecting to an entity in a bodily domain (i.e., touching). In a marketing context, this conceptualization is particularly reflected by Escalas and Bettman's (2003) notion of self-brand connections, which describe the extent to which individuals incorporate an intangible brand into their self-concept. Hence, our understanding of psychological connection is similar to related constructs such as psychological ownership and attachment (Belk 1988; Pierce et al. 2001; Mifsud et al. 2015) which also address consumers' emotional and self-definitional connections to external entities. This understanding of psychological connection leads to various specific assumptions that we test in this paper.

Referring to embodied cognition, we argue that giving consumers the opportunity to physically touch an object that is associated with a service eases consumers' psychological connection to that service (Ackerman et al. 2010). For example, touching a mug associated with a certain service provider may strengthen consumers' psychological connection to the provider. Hence, the physical connection to the object may serve as a metaphor for the psychological connection to the service. 
Furthermore, we argue that the psychological connection induced by physically connecting to an object leads to behavior that is in line with this psychological connection. Support for this argumentation comes from various previously mentioned studies. Williams and Bargh (2008a), for example, report that exposing individuals to a warm stimulus may not only result in a more positive, social assessment of a counterpart; importantly, it may also result in more pronounced social behavior. In a similar vein, Ackerman et al. (2010) highlight that exposing individuals to particularly hard stimuli makes social counterparts appear more strict and stable; however, above that it may also reduce individuals' flexibility in a negotiation situation with these counterparts (see also Hong and Sun 2012). Hence, according to these studies, physical sensations metaphorically transform into mental sentiments which again induce behaviors that correspond to these sentiments.

Transferred to this study's context, we argue that an individual's psychological connection to a service (induced by touching a service object) leads to more positive behavioral intentions towards the corresponding service. This proposed relationship between psychological connection and behavioral intentions is also supported by research in the context of self-brand connections and brand-oriented behavior. As such, a wide range of studies in this field supports the notion that emotional connections between consumers and brands translate into positive behaviors towards the concerned brands (e.g., brand loyalty) due to consumers' perceived bond and increased involvement with the brands (e.g., Fournier and Yao 1997; Loureiro et al. 2012; Kressmann et al. 2006). Hence, one can expect that a stronger psychological connection to a service induced by touching a tangible service object leads to more positive behavioral intentions towards the service. In sum, we hypothesize:

H1a: Consumers who touch a tangible service object exhibit more positive behavioral intentions towards the service compared to consumers who do not touch the object.

The hypothesis regarding the underlying process reads as follows:

H1b: The effect of touching a tangible service object on behavioral intentions is mediated by the psychological connection between consumers and the service.

We acknowledge that there may be alternative explanations for the positive behavioral impact of touching an object that are based on consumer research on touch. According to this stream of research, touching an object can result in feelings of psychological ownership towards the object itself (i.e., the feeling that something is "mine") and may therefore lead to a better evaluation of the object (Peck and Shu 2009). Such findings have been related to endowment effects according to which individuals' perceived value of an object increases when the object is owned or perceived as owned (Thaler 1980; Kahneman et al. 1990; Reb and Connolly 2007). Referring to these findings, one may suggest that touching an object associated with a service causes positive behavioral intentions due to an increase in feelings of ownership towards the object. Moreover, touching an object may also elicit a positive affective response, especially when consumers have a high need for touch (Peck and Wiggins 2006). 
However, while these findings provide a clear explanation for the effect of touch on a psychological connection to the object itself (or, more specifically, psychological ownership of the object), they provide no clear rationale why touching an object should also affect consumers' responses to the associated service. In contrast, our theorizing via embodied cognition explicitly addresses the influence of the tangible object on the relationship between the consumer and the associated organization (see also Table 1). Nevertheless, we address the possibility that the hypothesized effect of touch on behavioral intentions is driven by these alternative processes in our empirical analysis.

\subsection{The moderating role of aesthetic appeal}

Embodied cognition argues that bodily experiences serve as metaphors for mental processes. If sensual information affects mental processes, then object properties may trigger metaphorically corresponding sentiments. As outlined above, object properties such as, for example, temperature, hardness, or roughness can indeed induce mental sentiments and behaviors that correspond to these properties (Williams and Bargh 2008a; Ackerman et al. 2010). If the warmth of a stimulus increases prosocial behavior (Ackerman et al. 2010), so may the sensory appeal of an object increase the psychological appeal to an associated entity. We thereby define aesthetic appeal as the attraction individuals perceive towards an object based on its sensual appearance (Townsend and Sood 2012). Importantly, the term appeal applies for physical, sensual experiences but is also metaphorically transferable to the psychological domain (just like the term connection). Thus, the aesthetic appeal of a tangible service object may trigger a generic approach motivation that may foster a psychological appeal to the corresponding service (Williams and Bargh 2008a; Ackerman et al. 2010). In sum, we postulate that touching (i.e., physically connecting to) an object should induce a more pronounced psychological connection to the service the more appealing the sensory touch experience is perceived. In other words:

$\mathrm{H} 2$ : The mediating effect of touch on behavioral intentions through psychological connection is moderated by an object's aesthetic appeal. Specifically, the effect of touch on psychological connection is stronger for objects that are more vs. less aesthetically appealing.

Figure 1 summarizes our conceptual model. In Study 1, we first investigate the basic relationship between touching a tangible service object and behavioral intentions towards the corresponding service as proposed by H1a and examine the mediating influence of psychological connection (i.e., H1b). We also use this study to test possible alternative explanations for the examined effects. In Study 2, we investigate the moderating role of aesthetic appeal proposed by $\mathrm{H} 2$. Studies 1 and 2 test the effect of touch on behavioral intentions before consumers' initial experience with the service. In contrast, Study 3 investigates the impact of touch in a field setting relating to an already existing customer-service provider relationship. This setting allows us to test whether touching a tangible service object also strengthens the relationship with existing customers in an actual service setting. 


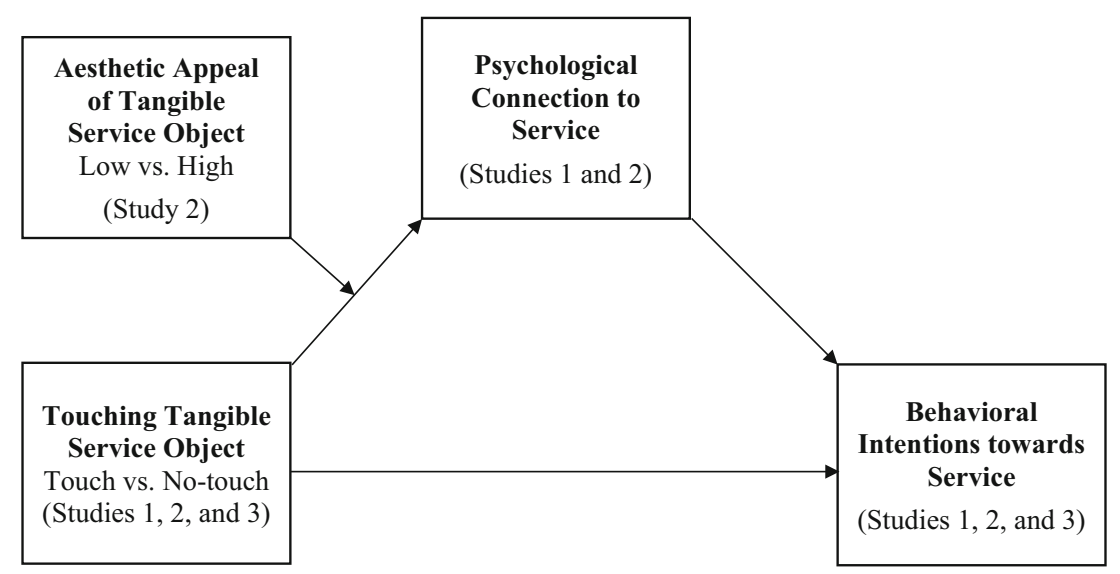

Fig. 1 Conceptual model

\section{Study 1}

\subsection{Overview and method}

The aim of Study 1 was to test H1a and H1b. That is, we tested whether physically connecting to an object associated with a service influences consumers' psychological connection to the service and, accordingly, their behavioral intentions towards the service. Furthermore, we used this first study to test alternative process explanations (compared to $\mathrm{H} 1 \mathrm{~b}$ ). As previously outlined, it is possible that touching an object associated with a service may cause positive behavioral intentions towards the service due to feelings of ownership towards the object itself (Peck and Shu 2009). Study 1 aimed to control for this alternative process explanation. Moreover, we intended to control for a reciprocity effect possibly caused by perceiving the object as a gift. According to the notion of reciprocity, individuals tend to reward kind actions of others (Falk and Fischbacher 2006).

Hence, Study 1 utilized a 2 (touch of object: touch vs. no-touch) $\times 2$ (transfer of legal ownership: transfer vs. no transfer) between-subjects design. We included the second factor in order to test whether merely touching the object (no transfer of legal ownership) already caused the postulated effects and, particularly, whether the observed effects were increased by a transfer of legal ownership. According to Peck and Shu (2009), touching the object as well as transfer of legal ownership should both increase psychological ownership of the object (see also Shu and Peck 2011). Hence, if the postulated effect of touch on behavioral intentions was mediated by psychological ownership of the object (instead of psychological connection to the service), then transferring legal ownership should induce an additional effect on behavioral intentions. Furthermore, in this case, the observed effects on behavioral intentions should be mediated by psychological ownership towards the object (see next section on utilized measures). Also, we expected more pronounced effects for conditions with legal ownership transfer on behavioral intentions if the effect was 
substantially caused by a reciprocity effect. In addition, we included one condition without an object to control for the overall presence of an object. A total of 145 students from a German university participated individually in the study (average age 21.6 years, $32.4 \%$ female). Twenty-nine of these participants were assigned to the non-factorial control group. Participants were run individually in a separated area of the university's entrance hall.

Participants were told that a café called "Gusto" was planning to open near campus and were asked to review the website of the café. They were also informed that the café would sell glasses to their guests and needed their input for pretesting these glasses. The website and the glasses were explicitly created for the study. In the touch conditions, the glass was provided on a table and participants were instructed to hold the glass. In the no-touch conditions, participants were shown an image of the glass. To manipulate transfer of ownership, half of the participants were told that they would receive the glass after completing the study (participants actually received the glass after the study) while the other half did not receive this information and the glass. Note that all participants who received the glass after the study wanted to keep it, indicating that they actually liked it. In the control condition, participants were neither exposed to the glass nor to a picture of the glass. All participants were given five minutes to review the stimulus materials and then responded to the dependent measures.

\subsection{Measures}

To operationalize touch and transfer of ownership, we created two effect-coded variables (touch: $-1=$ no touch, $1=$ touch; transfer of ownership: $-1=$ no transfer of ownership, 1 = transfer of ownership) as recommended by the literature (Landwehr 2019).

Behavioral intentions were measured using an adapted purchase intention scale from Berens et al. (2005). Specifically, participants responded to three items (If you were planning an evening with friends, how likely would it be that you tried the café "Gusto"?/Imagine a friend of you had asked you yesterday for a recommendation for a café! How likely is it that you would have suggested the café "Gusto"?/How likely will you try out the café "Gusto"?) on a 7-point scale anchored by very unlikely [1] and very likely [7]. The items were averaged to form a single measure of behavioral intentions $(\alpha=0.84)$.

To measure participants' psychological connection to the café "Gusto", we used the self-brand connection scale from Escalas and Bettman (2003; $\alpha=0.91)$. Specifically, participants responded to seven items (The café "Gusto" reflects who I am/I can identify with the café "Gusto"/I feel a personal connection to the café "Gusto"/The café "Gusto" matches the image that I want to communicate to others/ I think the café "Gusto" may help me become the person I want to be/The café "Gusto" says something about who I am/The café "Gusto" suits me well).

A three-item scale from Pierce et al. (2001) and Peck and Shu (2009) was used to control for a potential effect of psychological ownership of the glass (I feel like this is my glass/I feel a very high degree of personal ownership of the glass/I feel like I own this glass; $\alpha=0.83$ ). Participants also rated the visual appeal of the glass based 
on one item from Peck and Shu (2009: The glass looks pleasant). This item as well as the psychological connection scale and the psychological ownership scale were 7-point scales anchored by totally disagree [1] and totally agree [7]. As a manipulation check for the ownership manipulation, participants were asked if they were allowed to keep the glass (yes/no).

\subsection{Results}

To compare the aesthetic appeal of the glass between participants in the touch and no-touch condition, we relied on their indication of visual appearance as both groups could judge this dimension. All participants evaluated the visual appearance of the glass favorably $(M=4.57)$ and this judgment did not differ between the conditions $(p>0.16)$. Furthermore, all participants answered the ownership manipulation check correctly.

A $2 \times 2$ ANOVA revealed a significant effect of touch on behavioral intentions towards the service $(F(1,112)=17.24, p<0.001)$. The effect of transfer of ownership $(F(1,112)=2.63, p=0.11)$ and the touch $\times$ ownership interaction were not significant $(F(1,112)=0.06, p=0.80)$. That is, participants expressed more positive behavioral intentions in the touch condition than in the no-touch condition regardless of transfer of ownership (transfer: $M_{\text {no-touch }}=3.89, M_{\text {touch }}=4.71 ; F(1$, $112)=9.51, \quad p<0.01 ; \quad$ no transfer: $\quad M_{\text {no-touch }}=4.24, \quad M_{\text {touch }}=4.97 ; \quad F(1$, $112)=7.76, p<0.01)$. Pairwise comparisons between the experimental conditions and the control condition without the glass revealed that only touching the glass led to higher behavioral intentions, independent of whether participants received ownership of the glass or not $\left(M_{\text {control }}=3.86\right.$ vs. $M_{\text {touch transfer of ownership }}=4.71$, $p<0.01$; vs. $\left.M_{\text {touch no transfer of ownership }}=4.97, p<0.001\right)$. All other comparisons were not significant ( $p>0.17$ ). In sum, these findings support H1a (Fig. 2).

Next, we examined whether the impact of touch on behavioral intentions was mediated by psychological connection to the service and/or psychological ownership of the glass (see Table 2). To control for the influence of transfer of ownership, we included transfer of ownership and the touch $\times$ transfer of ownership interaction in the different models. First, we regressed psychological connection to the service on touch, transfer of ownership, and the touch $\times$ transfer of ownership interaction and found a significant effect for touch (touch: $b=0.32$, $t=3.77, p<0.001$; transfer of ownership: $b=-0.01, t=-0.08, p=0.93$; touch $\times$ transfer of ownership: $b=-0.04, t=-0.44, p=0.66$ ). Next, we regressed psychological ownership of the glass on the same variables which revealed a significant effect of touch and transfer of ownership (touch: $b=0.26$, $t=2.30, \quad p=0.02 ; \quad$ transfer of ownership: $b=0.24, \quad t=2.11, \quad p=0.04$; touch $\times$ transfer of ownership: $b=0.12, t=1.09, p=0.28)$. Finally, we tested a multi-mediator model ${ }^{2}$ including both potential mediators based on Hayes (2018; model 4). In this model, psychological connection to the service predicted

\footnotetext{
${ }^{2}$ Note that we also tested mediation models using psychological connection and psychological ownership as single mediators. This led to similar results. Moreover, a test of a serial mediation model with psychological ownership as the first mediator and psychological connection as the second mediator did not reveal a significant serial mediation effect.
} 


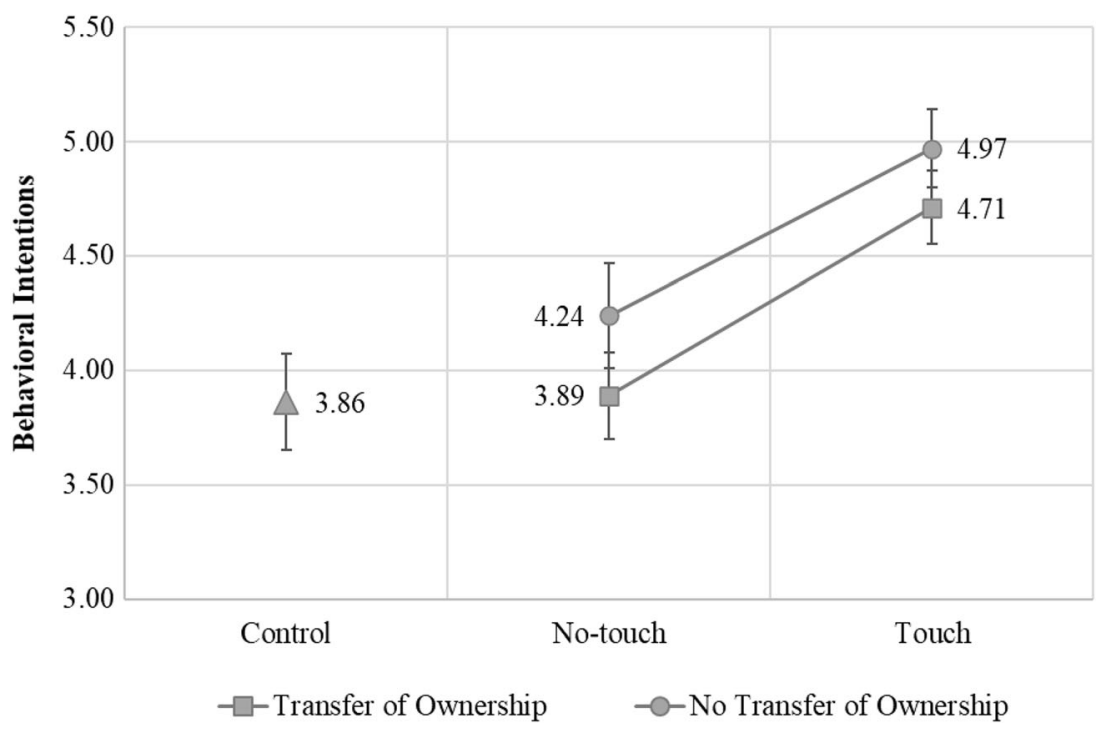

Fig. 2 Study 1: Effect of touch and transfer of ownership on behavioral intentions. Errors bars indicate standard errors

Table 2 Study 1: Model estimation results of the mediation analyses

\begin{tabular}{|c|c|c|c|c|c|c|}
\hline \multirow[t]{3}{*}{ Predictor } & \multicolumn{4}{|c|}{ Mediator models } & \multirow{2}{*}{\multicolumn{2}{|c|}{$\begin{array}{l}\text { Dependent variable } \\
\text { model with mediator } \\
\text { DV: behavioral } \\
\text { intentions }\end{array}$}} \\
\hline & \multicolumn{2}{|c|}{$\begin{array}{l}\text { DV: psychological } \\
\text { connection }\end{array}$} & \multicolumn{2}{|c|}{$\begin{array}{l}\text { DV: } \\
\text { psychological } \\
\text { ownership }\end{array}$} & & \\
\hline & $b$ & $t$ & $b$ & $t$ & $b$ & $t$ \\
\hline Touch & 0.32 & $3.77 * * *$ & 0.26 & $2.30 *$ & 0.25 & $2.65^{*}$ \\
\hline Transfer of ownership & -0.01 & -0.08 & 0.24 & $2.11^{*}$ & -0.16 & -1.82 \\
\hline Touch $\times$ transfer of ownership & -0.04 & -0.44 & 0.12 & 1.09 & 0.03 & 0.35 \\
\hline Psychological connection & & & & & 0.39 & $3.92 * * *$ \\
\hline Psychological ownership & & & & & 0.06 & 0.76 \\
\hline
\end{tabular}

$D V$ dependent variable

$* p<0.05, * * p<0.01, * * * p<0.001$

behavioral intentions ( $b=0.39, t=3.92, p<0.001$ ) while psychological ownership of the glass did not predict behavioral intentions $(b=0.06, t=0.76, p=0.45)$. Transfer of ownership and the touch $\times$ transfer of ownership interaction did not have a significant impact (transfer of ownership: $b=-0.16, t=-1.82, p=0.07$; touch $\times$ transfer of ownership: $b=0.03, t=0.35, p=0.72$ ) but touch remained significant $(b=0.25, t=2.65, p=0.01)$. These findings indicate partial mediation 
through psychological connection to the service only. The bootstrapping analysis (5000 resamples) suggested by Zhao et al. (2010) confirmed that the indirect effect of touch through psychological connection to the service was significant $[b=0.13$; $95 \%$ confidence interval $(\mathrm{CI})=(0.0353,0.2441)]$ but not the indirect effect of touch through psychological ownership of the glass $[b=0.01 ; 95 \%$ confidence interval $(\mathrm{CI})=(-0.0412,0.0666)]$. In sum, these findings support H1b.

\subsection{Discussion}

Study 1 provides initial support for H1a and H1b. Notably, both hypotheses are supported irrespective of whether legal ownership of the object was transferred to participants or not. The results indicate that behavioral intentions towards the service are mainly driven by the touch manipulation and a subsequent psychological connection to the service as opposed to individuals' psychological ownership of the object. While touching the object as well as the transfer of legal ownership increased individuals' perception of ownership of the glass itself (as expected and in line with the findings of Peck and Shu 2009), these effects did not transfer to positive behavioral intentions towards the corresponding service. At the same time, if the effect on behavioral intentions was caused by reciprocity effects, transfer of ownership should have increased behavioral intentions towards the service. In sum, the findings of Study 1 provide support for our theorizing based on the concept of embodied cognition. Building on these results, the following study will test the effect of more or less aesthetic objects on behavioral intentions towards services.

\section{Study 2}

\subsection{Overview and method}

The aim of Study 2 was to test H2. That is, we wanted to extend the previous findings by further considering the influence of an object's aesthetic appeal. Therefore, Study 2 used a 2 (touch of object: touch vs. no-touch) $\times 2$ (aesthetic appeal: low vs. high) between-subjects design. Again, we included an additional condition without an object in the study design to control for the general presence of an object. A total of 135 students from a German university (average age 20.7 years, $28.9 \%$ female) participated in the study. Twenty-seven of these participants were assigned to the non-factorial control group. Again, participants were run individually in a separated area of the university's entrance hall. Participants were told that a gym was about to open soon and were asked to review the gym's website. Moreover, participants were informed that the gym would introduce membership wristbands. In the touch condition, participants were asked to wear the wristband while looking at the website. In the no-touch condition, participants were shown an image of the wristband. Similar to Study 1, the website and the wristbands were explicitly created for the study. To manipulate aesthetic appeal, we used two types of plastic wristbands differing in their appeal through the usage of more or less 
appealing materials. That is, the low-appeal wristband was made of thinner plastic, whereas the high-appeal wristband was made of thicker, more stable plastic. To prevent unintended effects, we kept all other aspects of the wristbands' design as similar as possible between the conditions. All participants were given five minutes to review the website and were then asked to respond to the dependent measures.

\subsection{Measures}

Similar to Study 1, we created two effect-coded variables to operationalize the independent variables (touch: $-1=$ no touch, $1=$ touch; aesthetic appeal: $-1=$ low, $1=$ high). We measured behavioral intentions $(\alpha=0.74)$ and psychological connection $(\alpha=0.88)$ with the same items as in Study 1 and adapted the items to the new study context. We used a manipulation check to assess the effectiveness of the appeal manipulation. This check slightly differed depending on whether participants only saw a picture of the wristbands or touched them. All participants rated the aesthetic appeal of the wristbands based on the wristbands' visual appearance on two items (The wristband has a high-grade look/The wristband looks stable, $r=0.64$ ). Participants in the touch conditions additionally evaluated their haptic appeal on two further items (The wristband has a high-grade feel/The wristband has a stable feel, $r=0.69$ ).

\subsection{Results}

Participants who were exposed to the high-appeal wristband rated its visual appearance more positively than participants exposed to the low-appeal wristband $\left(M_{\text {high appeal }}=4.56, M_{\text {low appeal }}=3.28 ; F(1,104)=23.37, p<0.001\right)$. Participants in the touch conditions evaluated the haptic appeal of the wristband more positively when they received the high-appeal version $\left(M_{\text {high appeal }}=4.52, M_{\text {low } \text { appeal }}=3.11\right.$; $F(1,52)=13.38, p<0.01)$. However, no differences were found in visual appeal ratings between the touch and no-touch condition for the low appeal wristband $(p>0.11)$ as well as for the high appeal wristband $(p>0.88)$. Hence, participants' appeal ratings were similar independent of whether they touched the wristband or not.

$\mathrm{H} 2$ proposes a case of moderated mediation, in which aesthetic appeal moderates the impact of touch on psychological connection (the mediator), which, in turn, influences behavioral intentions. First, we ran a $2 \times 2$ ANOVA for behavioral intentions. This analysis revealed a marginally significant effect for touch $(F(1$, $104)=3.38, p=0.069)$ and a significant effect for appeal $(F(1,104)=4.48$, $p=0.04)$. Importantly, the touch $\times$ appeal interaction was significant $(F(1$, $104)=6.28, p=0.01)$. As Fig. 2 shows, touching the wristband only affected behavioral intentions when the wristband was of high appeal (high appeal: $M_{\text {touch }}=4.94, M_{\text {no-touch }}=3.98 ; F(1,104)=9.44, p<0.01 ;$ low appeal: $M_{\text {touch- }}$ $\left.=3.91, M_{\text {no-touch }}=4.06 ; F(1,104)=0.22, p=0.63\right)$. Pairwise comparisons with the control condition revealed that behavioral intentions only differed significantly from the control condition when participants touched the high-appeal wristband 
Table 3 Study 2: Model estimation results of the moderated mediation analyses

\begin{tabular}{|c|c|c|c|c|}
\hline \multirow[t]{3}{*}{ Predictor } & \multicolumn{2}{|c|}{ Mediator model } & \multicolumn{2}{|c|}{ Dependent variable model with mediator } \\
\hline & \multicolumn{2}{|c|}{ DV: psychological connection } & \multicolumn{2}{|c|}{ DV: behavioral intentions } \\
\hline & $b$ & $t$ & $b$ & $t$ \\
\hline Touch & 0.16 & 1.86 & 0.10 & 1.04 \\
\hline Aesthetic appeal & 0.23 & $2.70 * *$ & 0.09 & 0.87 \\
\hline Touch $\times$ aesthetic appeal & 0.35 & $4.06^{* * *}$ & 0.06 & 0.54 \\
\hline Psychological connection & & & 0.64 & $5.72 * * *$ \\
\hline
\end{tabular}

$D V$ dependent variable

$* p<0.05, * * p<0.01, * * * p<0.001$

$\left(M_{\text {control }}=4.31, M_{\text {touch high appeal }}=4.94, p=0.04\right)$. All other comparisons were not significant $(p>0.22)$.

Next, we performed regression analyses (see Table 3). In the mediator model, we regressed psychological connection on touch, aesthetic appeal, and the touch $\times$ aesthetic appeal interaction. This analysis indicated that psychological connection was predicted by the touch $\times$ aesthetic appeal interaction $(b=0.35, t=4.06$, $p<0.001)$. We also found a significant effect for aesthetic appeal and a marginally significant effect for touch (aesthetic appeal: $b=0.23, t=2.70, p<0.01$; touch: $b=0.16, t=1.86, p=0.066)$. In the dependent variable model, the interaction effect between touch and aesthetic appeal was not significant $(b=0.06, t=0.54$, $p=0.59)$. At the same time, the effect of psychological connection on behavioral intentions was significant ( $b=0.64, t=5.72, p<0.001$ ), thus indicating moderated mediation. Using the bootstrapping method (Hayes 2018, model 8), the indirect effect of touch on behavioral intentions via psychological connection was significant for high-appeal wristbands $[b=0.32,95 \% \mathrm{CI}=(0.1872,0.4888)]$ but not significant for low-appeal wristbands $[b=-0.12,95 \% \quad \mathrm{CI}=(-0.3197$, 0.0505)], indicating a mediation effect of psychological connection. The confidence interval for the index of moderated mediation did not include zero [0.44, 95\% $\mathrm{CI}=(0.2115 ; 0.7287)]$, indicating that the mediation is moderated. In sum, these findings support $\mathrm{H} 2$ (Fig. 3).

\subsection{Discussion}

As expected, Study 2 showed that touching a tangible service object only led to more positive behavioral intentions when the object had a positive aesthetic appeal. These results support our argument that it is not the appeal of the object per se that strengthens individuals' connection to the service but the ability to physically connect to the appealing object. At the same time, these results render an explanation based on the quality-indicating function of aesthetically appealing objects less likely. If our results were primarily driven by a quality-indicating function, the effect of high vs. low appeal should have occurred for the touch as well 


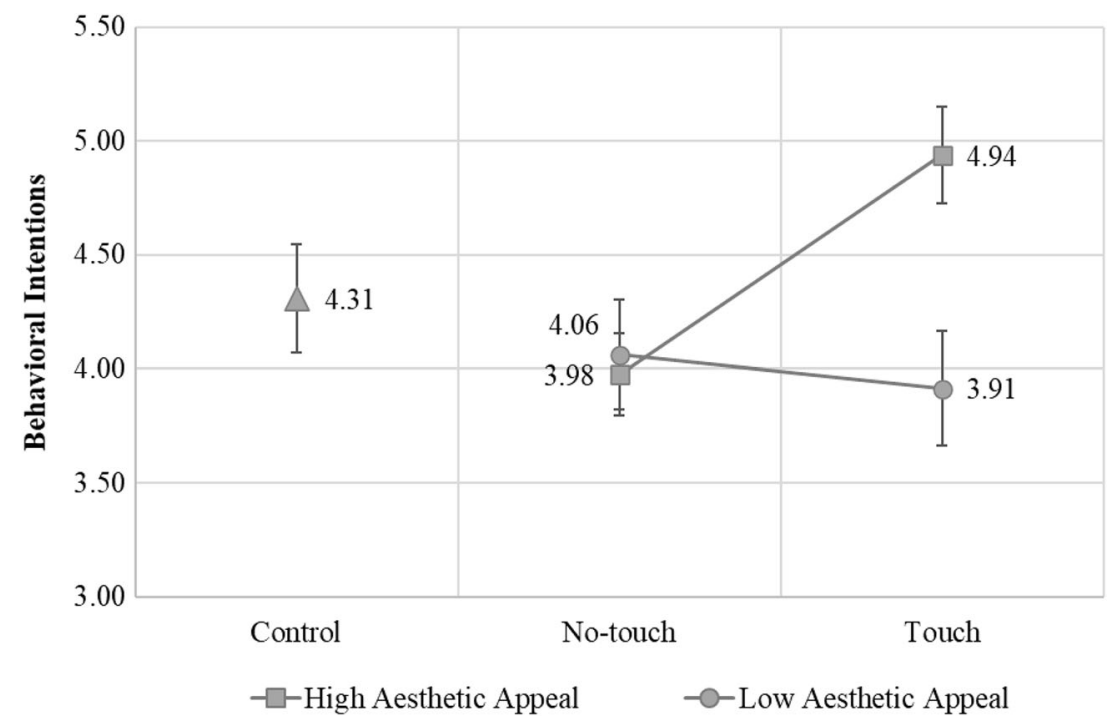

Fig. 3 Study 2: Touch and aesthetic appeal interact to affect behavioral intentions. Errors bars indicate standard errors

as for the no-touch conditions. Hence, our results support the notion that the effect is mainly driven by a body-related reaction to the object as postulated by embodied cognition.

\section{Study 3}

\subsection{Overview and method}

The aim of Study 3 was to retest the main hypothesis H1a in a field setting. Therefore, we cooperated with a local gym and tested whether we could use objects connected to the gym to enhance behavioral intentions towards the gym. In contrast to the previous studies, participants in this study were already customers of the service. This setting allowed for a more conservative testing of our hypothesis. Since participants already knew the gym, we presumed that they already had a psychological connection to the service provider. However, our prestudy indicated that, in general, consumers have a weaker connection to providers of regularly used services compared to those of products. Hence, in this study the objects were not used to initiate a psychological connection between consumers and a service provider as in Studies 1 and 2 but to strengthen customers' perception of such a connection in an already existing customer-service provider relationship.

We approached gym members when entering the gym under the pretext of a customer satisfaction survey. To enhance the generalizability of our results, members were randomly exposed to different types of appealing objects: either a drinking bottle or a pen, both showing the gym logo. The gym members were told 
that they would receive the objects as a thank-you gift for participating in the study. In half of the conditions, the experimenter put the object directly in the hands of participants. In the other half, participants were shown a picture of the object and were told that they would receive the object after completion of the study. Accordingly, we used a 2 (touch of object: touch vs. no-touch) $\times 2$ (object type: drinking bottle vs. pen) between-subjects design. The second factor was used as a replication factor. A total of 108 members (average age: 40.2 years, average years of membership: 6.02 years, $37.7 \%$ female) participated in the study. Participants were run individually.

\subsection{Measures}

Behavioral intentions were measured with two items from the previously used scale (Imagine you were searching for a gym. How likely would you choose MEGAFIT again?/Imagine a friend would ask you for a gym recommendation. How likely would you recommend MEGAFIT to him/her? $\alpha=0.90)$. Note that one item of the original scale was excluded as it did not apply to the setting of the study. We controlled for the objects' aesthetic appeal, asking participants about the visual appeal of the object (The bottle/pen has an appealing look). In the touch condition, participants also rated the haptic appeal of the object. (The bottle/pen has an appealing touch).

\subsection{Results}

All participants rated the visual appeal of the object favorably $(M=4.49)$ and this judgment did not differ between conditions $(p>0.38)$. Furthermore, no significant differences were found in haptic appeal ratings between the bottle and the pen in the touch condition $(p>0.37)$.

A $2 \times 2$ ANOVA revealed a significant effect for touch $(F(1,104)=13.45$, $p<0.001)$ and insignificant effects for object type $(F(1,104)=0.01, p>0.92)$ and the touch $\times$ object type interaction $(F(1,104)<0.01, p>0.98)$ on behavioral intentions. In line with $\mathrm{H} 1 \mathrm{a}$, participants reported more positive behavioral intentions in the touch condition compared to the no-touch condition irrespective of which object was presented to them (bottle: $M_{\text {touch }}=5.30, M_{\text {no-touch }}=4.19, F(1$, $104)=6.71, p<0.02$, pen: $M_{\text {touch }}=5.27, M_{\text {no-touch }}=4.15, F(1,104)=6.73$, $p<0.02)$.

\subsection{Discussion}

Study 3 provides support for H1a in a field setting using two different types of objects. In addition, Study 3 suggests that the use of service objects is not restricted to services that consumers have no experience with but may also be an appropriate measure to increase behavioral intentions in an existing customer-service provider relationship. 


\section{General discussion}

The aim of this research was to investigate how the provision of tangible objects associated with a service affects consumers. We hypothesized that the sensory experience of touching a tangible object helps consumers to psychologically connect to a service, which, in turn, results in more positive behavioral intentions towards the service. Three experimental studies support this notion. Study 1 showed a positive effect of touching an object on behavioral intentions towards a service provider via psychological connection. Notably, this effect was stable independent of whether participants received legal and/or perceived ownership of the object. Study 2 extended these findings by showing that the opportunity to touch a tangible service object only led to a stronger psychological connection and to more positive intentions when the object had a high aesthetic appeal. This finding supports the notion that providing tangible objects triggers a bodily-related, sensory reaction in contrast to a purely cognitive attribution of properties from the object to the service. Finally, Study 3 replicated the main effect in a realistic field setting and showed that tangible objects may not only be used to connect with new customers but also to strengthen the relationship with existing customers.

\subsection{Theoretical implications}

These findings make several theoretical contributions. First, our research is one of the first to demonstrate that tangible service objects are more than trivial giveaways. On the contrary, our studies show that providing tangible service objects may affect consumers' psychological connection and behavioral intentions towards a service. In doing so, our research adds to previous research on the impact of servicescapes and giveaways. So far scholars have argued that physical components of the servicescape such as a building's design and décor are crucial as consumers may rely on these elements to infer service quality (e.g., Baker et al. 2002; Wakefield and Blodgett 1999). Others have argued that objects given to consumers are regarded as relationship investments which may stimulate reciprocation behaviors of existing customers (e.g., Marchand et al. 2017; Bodur and Grohmann 2005). Our findings extend these perspectives by demonstrating that tangible objects may also help to establish a connection between consumers' selves and a service before consumers have experienced the actual servicescape and before the service has been delivered. Moreover, our findings add to the literature by showing that the provision of service objects during and after service consumption may strengthen existing relationships with customers because such objects provide an (additional) opportunity for customers to connect to the service (note, however, that we do not claim that providing tangible objects renders other important service aspects such as interactions with service employees less important). In sum, our findings provide a new perspective on the impact of a specific element of the extended servicescape (Rosenbaum and Massiah 2011).

Second, our study contributes to research on the sensory design of service experiences by specifying the requirements that tangible objects need to fulfill to 
have an effect (Zomerdijk and Voss 2010). In this regard, our findings suggest that the provision of a tangible object will only have a positive impact on downstream variables if consumers can touch it and if it has a positive aesthetic appeal. In other words, providing a touchable object with a low aesthetic appeal may be as ineffective as providing an object with a high aesthetic appeal which consumers cannot touch. One may also argue that the sensory design of tangible objects may be more important for consumers than non-sensory aspects such as the type of object (in our studies, we obtained similar results for very different objects such as wristbands, drinking bottles, or pens).

Third, our work contributes to consumer research on the effects of touch. Studies in this field show that touching a product increases consumers' valuation of a product. This effect has been explained by an increase in feelings of psychological ownership of the touched object (e.g., Peck and Shu 2009). That is, when consumers touch an object, they have a stronger feeling that the object is "theirs" (Peck and Shu 2009). Furthermore, Peck and Wiggins (2006) argue that individuals with a high need for touch may affectively react to touch elements. Our research adds a further facet to consumers' reactions to touch based on embodied cognition theory. We show that touching an object may not only enhance individuals' valuation of the object (Peck and Shu 2009), but also offer a possible explanation why, above that, touching an object may also improve consumers' perceived connection with and behavioral intentions towards the entity associated with the object.

Finally, to our knowledge, this is the first research to apply the concept of embodied cognition in a service context. If services are generally perceived as more abstract than traditional products, then embodied cognition provides an interesting theoretical approach for service research, especially for research with regard to the impact of servicescapes. More specifically, embodied cognition highlights the question if and how the possibility to bodily grasp elements of the servicescape influences a consumer's assessment of and behavior towards an abstract service. Hence, our research may be seen as a starting point to integrate knowledge derived from embodied cognition to service research and related fields.

\subsection{Managerial implications}

The issues addressed in this research also have managerial implications. The most straightforward one is that it is recommendable for service firms to give tangible objects to consumers such as membership bracelets, mugs, pens or clothing articles. Giving objects to consumers may facilitate a connection between consumers and the service (at early but also at later interaction and relationship stages), thereby increasing behavioral intentions towards the service. For example, the Eibsee hotel, a mountain resort near a skiing area in the Alps, sends an ice scraper with an aesthetic picture of the hotel surrounded by the snowy Alpine landscape to potential customers at the beginning of each winter season. Recipients may perceive this ice scraper as a symbol of a winterly stay at the hotel. Hence, touching the ice scraper may not only lead to a physical connection between recipients and the ice scraper but also to a psychological connection between recipients and the hotel associated with the ice scraper. 
Importantly, as our findings suggest, the positive effects of such service objects may critically depend on touching the objects. The provision of virtual giveaways (e.g., online magazines, virtual greeting cards, online games) may not lead to similar effects because customers cannot touch these objects. Hence, managers may be well advised to use objects that customers can actually touch physically. Online retailers such as Westwing or Zalando, for example, send tangible objects to consumers by mail such as catalogues or gift cards, although these objects could easily be provided by e-mailings and other forms of digital marketing.

Another important implication of our research is that managers should only provide objects that have a high aesthetic appeal. For example, the bank mentioned in the introduction may undermine the positive impact of providing a document folder if the folder is not considered to be appealing. Hence, managers should put great emphasis on the overall aesthetics of the utilized objects. In many instances, this may imply a perspective change. That is, service objects should not be viewed as trivial giveaways that are simply selected from providers that offer standardized and interchangeable items with logo imprints. Instead, service objects should be perceived as a meaningful opportunity to physically and, hence, also emotionally connect with consumers. This requires a thoughtful and design-oriented approach towards such objects. The Swiss bank UBS, for example, gives friendship bracelets to their customers. To develop a highly aesthetic design, the bank cooperated with the luxury brand Bottletop which uses sustainable materials and top-level designs for their accessories. In total, the bank offers their customers 17 different, modernlooking bracelets available in different colors and materials.

Finally, our findings show that tangible objects may not only be useful to acquire new customers but also to retain existing customers. In this respect, the findings of Study 3 suggest that customers who touch a tangible service object are more likely to demonstrate loyalty behaviors. Hence, managers may be well advised to integrate tangible objects into their relationship marketing activities. A well-known service provider that has even created a business model based on this idea is the Hard Rock Cafe. The restaurant is well known for offering customers a wide range of tangible "take-aways" such as T-shirts, sweaters, magnets, or mugs that customers can buy as part of their visit to the restaurants. In our view, this is an outstanding example of utilizing tangible objects in order to "stay in touch" with customers even in-between service intervals. The fact that customers are willing to spend substantial amounts for such objects shows that these objects indeed have value for customers and that there is a need for customers to emotionally connect to service providers, even in situations in which they cannot experience the service directly. Referring to our earlier arguments, it is also worth mentioning that the Hard Rock Cafe does not use standardized objects but has developed its own line of recognizable, aesthetic objects.

\subsection{Limitations and future research}

While shedding new light on research about servicescape elements and touch, our studies also have some limitations that call for future research. First, we used controlled experiments to isolate the effect of touching service objects. Although we conducted Study 3 in a field setting and used unobtrusive manipulations, 
participants may have considered the design of our studies somewhat artificial. Hence, future research may want to investigate the impact of tangible service objects in more natural settings.

Second, we measured the dependent variables shortly after participants had been exposed to the tangible object. However, one may argue that customers touch certain objects repeatedly and over extended periods of time (e.g., a membership wristband in a gym). Thus, consumers may develop a stronger connection to the service when they are able to touch and hold an object for longer periods of time. Although our studies demonstrate that behavioral intentions may increase even after briefly touching an object, future research may want to explicitly manipulate the time that consumers are allowed to touch an object and/or measure behavioral intentions at different points of time.

Third, besides highlighting the relevance of aesthetic appeal, we did not specify what kinds of objects are particularly suitable for establishing a psychological connection between consumers and services. Also, we did not investigate whether certain types of service providers may particularly benefit from service objects. Future research may pay closer attention to these contextual factors and to the question of how the functional and/or symbolic connection between an object and a service influences the effects revealed in this research.

Fourth, to account for the underlying process, we focused on the mediating effect of psychological connection and distinguished this effect from any effects resulting from psychological ownership of the service object. While our results indicate that these two constructs are empirically distinct, they do share some conceptual similarities in that both constructs refer to how consumers emotionally connect to an external entity and incorporate this entity into their self-concept. Hence, a possible avenue for future research could be to more fully examine the similarities and differences between these two constructs and their specific effects on consumers' evaluations and choices.

Finally, in our studies we focused on one type of servicescape elements-objects that consumers can touch. Scholars may investigate if similar effects exist for other types of servicescape elements. For example, an interesting question would be if touching elements of a service facility's interior or exterior also increases behavioral intentions. As customers frequently touch elements of a service facility (e.g., customers at a bar touching the counter, a patient lying in a bed or being treated in a stool), touching these elements may also increase customers' connection and behavioral intentions towards a service. Research that investigates such questions is needed to facilitate a better management of physical elements in the service process.

Open Access This article is licensed under a Creative Commons Attribution 4.0 International License, which permits use, sharing, adaptation, distribution and reproduction in any medium or format, as long as you give appropriate credit to the original author(s) and the source, provide a link to the Creative Commons licence, and indicate if changes were made. The images or other third party material in this article are included in the article's Creative Commons licence, unless indicated otherwise in a credit line to the material. If material is not included in the article's Creative Commons licence and your intended use is not permitted by statutory regulation or exceeds the permitted use, you will need to obtain permission directly from the copyright holder. To view a copy of this licence, visit http:// creativecommons.org/licenses/by/4.0/. 


\section{References}

Ackerman, Joshua M., Christopher C. Nocera, and John A. Bargh. 2010. Incidental haptic sensations influence social judgments and decisions. Science 328 (5986): 1712-1715.

Baker, Julie, A. Parasuraman, Dhruv Grewal, and Glenn B. Voss. 2002. The influence of multiple store environment cues on perceived merchandise value and patronage intentions. Journal of Marketing 66 (2): 120-141.

Barsalou, Lawrence W. 2008. Grounded cognition. Annual Review of Psychology 59 (1): 617-645.

Belk, Russell W. 1988. Possessions and the extended self. Journal of Consumer Research 15 (2): 139-168.

Beltramini, Richard F. 1992. Exploring the effectiveness of business gifts: A controlled field experiment. Journal of the Academy of Marketing Science 20 (1): 87-91.

Berens, Guido, Cees B.M. van Riel, and Gerrit H. van Bruggen. 2005. Corporate associations and consumer product responses: The moderating role of corporate brand dominance. Journal of Marketing 69 (3): 35-48.

Bitner, Mary Jo. 1992. Servicescapes: The impact of physical surroundings on customers and employees. Journal of Marketing 56 (2): 57-71.

Bodur, H.Onur, and Bianca Grohmann. 2005. Consumer responses to gift receipt in business-to-consumer contexts. Psychology \& Marketing 22 (5): 441-456.

Dagger, Tracey S., and Peter J. Danaher. 2014. Comparing the effect of store remodeling on new and existing customers. Journal of Marketing 78 (3): 62-80.

Dorsch, Michael J., and Scott W. Kelley. 1994. An investigation into the intentions of purchasing executives to reciprocate vendor gifts. Journal of the Academy of Marketing Science 22 (4): $315-327$.

Escalas, Jennifer E., and James R. Bettman. 2003. You are what they eat: The influence of reference groups on consumers' connections to brands. Journal of Consumer Psychology 13 (3): 339-348.

Falk, Armin, and Urs Fischbacher. 2006. A theory of reciprocity. Games and Economic Behavior 54 (2): 293-315.

Fournier, Susan, and Julie L. Yao. 1997. Reviving brand loyalty: A reconceptualization within the framework of consumer-brand relationships. International Journal of Research in Marketing 14 (5): 451-472.

Hayes, Andrew F. 2018. Introduction to mediation, moderation, and conditional process analysis: A regression-based approach, 2nd ed. New York: The Guilford Press.

Hong, Jiewen, and Yacheng Sun. 2012. Warm it up with love: The effect of physical coldness on liking of romance movies. Journal of Consumer Research 39 (2): 293-306.

Hooper, Daire, Joseph Coughlan, and Michael R. Mullen. 2013. The servicescape as an antecedent to service quality and behavioral intentions. Journal of Services Marketing 27 (4): 271-280.

Jang, SooCheong (Shawn), and Young Namkung. 2009. Perceived quality, emotions, and behavioral intentions: Application of an extended Mehrabian-Russell model to restaurants. Journal of Business Research 62 (4): 451-460.

Kahneman, Daniel, Jack L. Knetsch, and Richard H. Thaler. 1990. Experimental tests of the endowment effect and the coase theorem. Journal of Political Economy 98 (6): 1325-1348.

Kressmann, Frank, M. Joseph Sirgy, Andreas Herrmann, Frank Huber, Stephanie Huber, and Dong-Jin Lee. 2006. Direct and indirect effects of self-image congruence on brand loyalty. Journal of Business Research 59 (9): 955-964.

Krishna, Aradhna. 2012. An integrative review of sensory marketing: Engaging the senses to affect perception, judgment and behavior. Journal of Consumer Psychology 22 (3): 332-351.

Krishna, Aradhna, and Norbert Schwarz. 2014. Sensory marketing, embodiment, and grounded cognition: A review and introduction. Journal of Consumer Psychology 24 (2): 159-168.

Lakoff, George, and Mark Johnson. 2003. Metaphors we live by. Chicago: The University of Chicago Press.

Landwehr, Jan R. 2019. Analysis of variance. In Handbook of market research, ed. Christian Homburg, Martin Klarmann, and Arnd Vomberg, 1-33. Cham: Springer International Publishing.

Laroche, Michel, Jasmin Bergeron, and Christine Goutaland. 2001. A three-dimensional scale of intangibility. Journal of Service Research 4 (1): 26-38. 
Loureiro, Sandra Maria Correia, Hans Ruediger Kaufmann, and Vrontis Demetris. 2012. Brand emotional connection and loyalty. Journal of Brand Management 20 (1): 13-27.

Marchand, André, Michael Paul, Thorsten Hennig-Thurau, and Georg Puchner. 2017. How gifts influence relationships with service customers and financial outcomes for firms. Journal of Service Research 20 (2): 105-119.

Mari, Michela, and Sara Poggesi. 2013. Servicescape cues and customer behavior: A systematic literature review and research agenda. The Service Industries Journal 33 (2): 171-199.

Mifsud, Matthieu, Anne-Sophie Cases, and Gilles N'Goala. 2015. Service appropriation: How do customers make the service their own? Journal of Service Management 26 (5): 706-725.

Mitra, Kaushik, Michelle C. Reiss, and Louis M. Capella. 1999. An examination of perceived risk, information search and behavioral intentions in search, experience and credence services. Journal of Services Marketing 13 (3): 208-228.

Mittal, Banwari. 1999. The advertising of services: Meeting the challenge of intangibility. Journal of Service Research 2 (1): 98-166.

Orth, Ulrich R., and Jochen Wirtz. 2014. Consumer processing of interior service environments: The interplay among visual complexity, processing fluency, and attractiveness. Journal of Service Research 17 (3): 296-309.

Peck, Joann, and Terry L. Childers. 2003. To have and to hold: The influence of haptic information on product judgments. Journal of Marketing 67 (2): 35-48.

Peck, Joann, and Suzanne B. Shu. 2009. The effect of mere touch on perceived ownership. Journal of Consumer Research 36 (3): 434-447.

Peck, Joann, and Jennifer Wiggins. 2006. It just feels good: Customers' affective response to touch and its influence on persuasion. Journal of Marketing 70 (4): 56-69.

Pierce, John L., Tatiana Kostova, and Kurt T. Dirks. 2001. Towards a theory of psychological ownership in organizations. Academy of Management Review 26 (2): 298-310.

Reb, Jochen, and Terry Connolly. 2007. Possession, feelings of ownership and the endowment effect. Judgment and Decision Making Journal 2 (2): 107-114.

Rosenbaum, Mark S. 2009. Restorative servicescapes: Restoring directed attention in third places. Journal of Service Management 20 (2): 173-191.

Rosenbaum, Mark S., and Carolyn Massiah. 2011. An expanded servicescape perspective. Journal of Service Management 22 (4): 471-490.

Shu, Suzanne B., and Joann Peck. 2011. Psychological ownership and affective reaction: Emotional attachment process variables and the endowment effect. Journal of Consumer Psychology 21 (4): 439-452.

Thaler, Richard. 1980. Toward a positive theory of consumer choice. Journal of Economic Behavior \& Organization 1 (1): 39-60.

Townsend, Claudia, and Sanjay Sood. 2012. Self-affirmation through the choice of highly aesthetic products. Journal of Consumer Research 39 (2): 415-428.

Wakefield, Kirk L., and Jeffrey G. Blodgett. 2016. Retrospective: The importance of servicescapes in leisure service settings. Journal of Services Marketing 30 (7): 686-691.

Wakefield, Kirk L., and Jeffrey G. Blodgett. 1996. The effect of the servicescape on customers' behavioral intentions in leisure service settings. Journal of Services Marketing 10 (6): 45-61.

Wakefield, Kirk L., and Jeffrey G. Blodgett. 1999. Customer response to intangible and tangible service factors. Psychology \& Marketing 16 (1): 51-68.

Wakefield, Kirk L., and Jeffrey G. Blodgett. 1994. The importance of servicescapes in leisure service settings. Journal of Services Marketing 3: 66-76.

Wells, Gary L., and Richard E. Petty. 1980. The effects of over head movements on persuasion: Compatibility and incompatibility of responses. Basic and Applied Social Psychology 1 (3): 219-230.

Williams, Lawrence E., and John A. Bargh. 2008a. Experiencing physical warmth promotes interpersonal warmth. Science 322 (5901): 606-607.

Williams, Lawrence E., and John A. Bargh. 2008b. Keeping one's distance: The influence of spatial distance cues on affect and evaluation. Psychological Science 19 (3): 302-308.

Zeithaml, Valerie A., and Mary Jo Bitner. 1996. Services marketing. New York: McGraw-Hill.

Zhao, Xinshu, John G. Lynch, and Qimei Chen. 2010. Reconsidering baron and kenny: Myths and truths about mediation analysis. Journal of Consumer Research 37 (2): 197-206. 
Zomerdijk, Leonieke G., and Christopher A. Voss. 2010. Service design for experience-centric services. Journal of Service Research 13 (1): 67-82.

Publisher's Note Springer Nature remains neutral with regard to jurisdictional claims in published maps and institutional affiliations. 